\title{
EDITORIAL
}

\section{National Health Insurance (NHI): Funding is an issue!}

On 10 December 2015, South Africa's Health Minister Dr. Aaron Motsoaledi, released the long awaited National Health Insurance (NHI) White Paper (version 40) providing the background and justification of the country's moves to join other countries like Brazil, United Kingdom and Thailand in introducing universal healthcare coverage. The document explains that healthcare in South Africa is comprised of a two-tiered system divided along socio-economic lines. The private medical aid sector comprising of 83 medical aid schemes that fund healthcare services for about 16 percent of the population. The paper noted that spending through medical schemes in South Africa is the highest in the world and is six times higher than in Organisation for Economic Co-operation and Development (OECD) countries. The White Paper clearly states that the NHI will deliver a comprehensive package of health services that include services such as rehabilitation and palliative care, mental health care including that related to substance abuse and maternal and child health care.

The 97-page White Paper is detailed in terms of population and service coverage, Primary Health Care $(\mathrm{PHC})$ re-engineering and strategies to enhance effectiveness of the health care system. It further defines the role, functions, management, and governance of hospitals and specialised services under the $\mathrm{NHI}$. However, the focus of this editorial is on the financing of this innovative system of healthcare funding in South Africa. The NHI projections set out in the Green Paper as modified in the White Paper indicate that the total NHI costs in 2025 will be R256 billion (in 2010 terms). The projections are expected to take the level of public health spending from approximately $4 \%$ to $6.2 \%$ of gross domestic product (GDP) by $2025 / 26$, with the assumption that the economy grows at an annual rate of $3.5 \% .{ }^{2}$ Hence the first hurdle for the $\mathrm{NHI}$ funding projections and assumption is the current economic growth of the country. The International Monetary Fund (IMF) has cut its forecast for economic growth in South Africa for a second time in 2016 as policy uncertainty increased and the central bank raised borrowing costs. The IMF forecasts that South Africa's GDP will probably expand by $0.6 \%$ in 2016, compared with January 2016's estimate of $0.7 \%$ and has lowered its projection for 2017 from $1.8 \%$ to $1.2 \%{ }^{3}$

The projection does not take into account the health system's absorptive capacity and personnel requirements or the dynamic of the accompanying public and private health sector reforms. The implication of the country's lowered GDP is that the projected NHI cost of R256 billion by 2025 may not be realised. In turn, the roll out of $\mathrm{NHI}$ throughout the country will have to be reviewed and revised. Another challenge is how to raise the revenue to finance the $\mathrm{NHI}$. The White Paper refers to potential revenue sources as follows: ${ }^{2}$

a. Direct taxation: Taxes imposed on individuals or entities in relation to their income, earnings or wealth

b. Indirect taxation: Taxes levied on transactions or goods and services, irrespective of circumstances of buyer or seller

c. Payroll taxation: Taxes calculated on payroll, as either employer or employee contribution, or both

d. Premiums: Collections of premiums or membership contributions from employee or informal sector

It proposes a mix of revenue sources without recommending any particular funding model. Therefore, the White Paper surmises that the NHI's financing requirements are uncertain, and in part depend on public health system improvements and medical scheme regulatory reforms, which have not yet been fully articulated. It is nonetheless possible to indicate the broad magnitude of tax changes that might be required. The economic landscape is rapidly changing with lowered economic growth forecast and possible downgrade. The relatively high unemployment scenario was not factored in the assumptions for the NHI funding. The reality is that version 40 of the White Paper has to be revised, as the projections and assumption made for its funding are no longer accurate to proceed with this innovative health-funding model.

There is an urgent need to engage health professionals, actuaries, and medical aid funders to review options on how to fund South Africa's NHI bearing in mind the current and foreseeable economic outlook. If this is not proactively processed, the government's health reforms will be a dream. We all want an equitable health care system that caters for the vast majority of its citizens. However, it must be affordable without incurring the additional tax burden on the pool of taxpayers. A healthy nation they say is a wealthy nation! Let us all work towards making the $\mathrm{NHI}$ a reality in our lifetime.

\section{Professor Gboyega A Ogunbanjo}

Editor-in-chief: SAFPJ

\section{References}

1. Health-E News. White paper: National Health Insurance for South Africa. https:// www.health-e.org.za/2015/12/14/white-paper-national-health-insurance-forsouth-africa/ (accessed 14 Aug 2016)

2. Department of Health. National Health Insurance for South Africa: Towards Universal Health Coverage. https://www.health-e.org.za/wp-content/uploads/2015/12/ National-Health-Insurance-for-South-Africa-White-Paper.pdf (accessed 14 Aug 2016)

3. Mail \& Guardian. IMF slashes SA growth forecast. http://mg.co.za/article/201604-12-imf-slashes-sa-growth-forecast/ (accessed 14 Aug 2016) 